
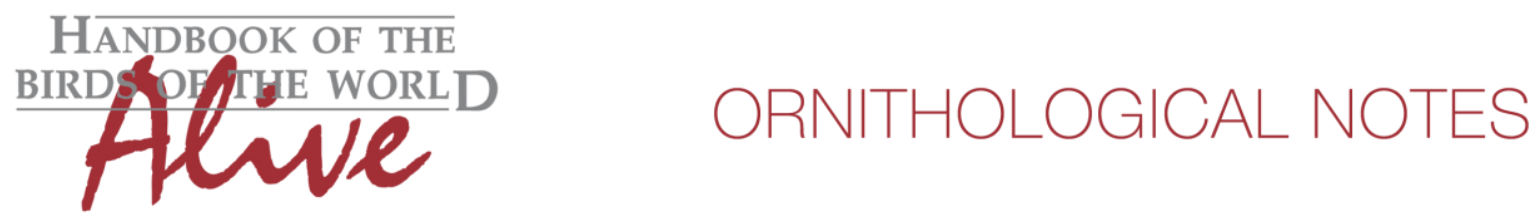

\title{
Notes on the vocalizations of Australian Logrunner (Orthonyx temminckii) and New-Guinean Logrunner (Orthonyx novaeguineae)
}

Peter Boesman

In the following we briefly analyze and compare voice of the different races of Australian Logrunner (Orthonyx temminckii) and New-Guinean Logrunner (Orthonyx novaeguineae). We also try to quantify the extent of any vocal differences using the criteria proposed by Tobias et al. (2010), as a support for taxonomic review. We have made use of sound recordings available on-line from Xeno Canto $(\mathrm{XC})$ and Macaulay Library (ML).

\section{temminckii}

Song and call are rather similar: a penetrating short, usually sharply upslurred note repeated several times, either in long series or in short bursts. Presumed song has notes slightly longer, less strident, and slightly more complex in shape, e.g. "kweek-kweek-kweek". Typical example:



Out of the 15 recordings, we have picked the ones which most resemble 'song'.

\section{Measurements:}

min. freq. (1st harmonic) $480-600 \mathrm{~Hz}$

max. freq. (1st harmonic) $2200-2800 \mathrm{~Hz}$

min. note length

$0.09-0.21 \mathrm{~s}$

max. note length

$0.14-0.22 \mathrm{~s}$

pace

$0.2-0.38 \mathrm{~s}$ (expressed as period, duration between 2 consecutive notes)

notes repeated

1 (repetitions always are of a single note $=$ simplest phrase) 


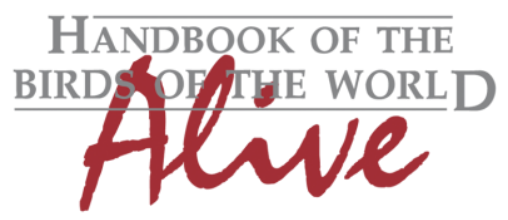

\section{ORNITHOLOGICAL NOTES}

\section{victorianus/dorsalis}

Song very different from Australian Logrunner: a repeated phrase of several pure melodious whistles. In its simplest form, a descending series of whistles, but also phrases consisting of more complex alternations in pitch.

simple example:



more complex examples:
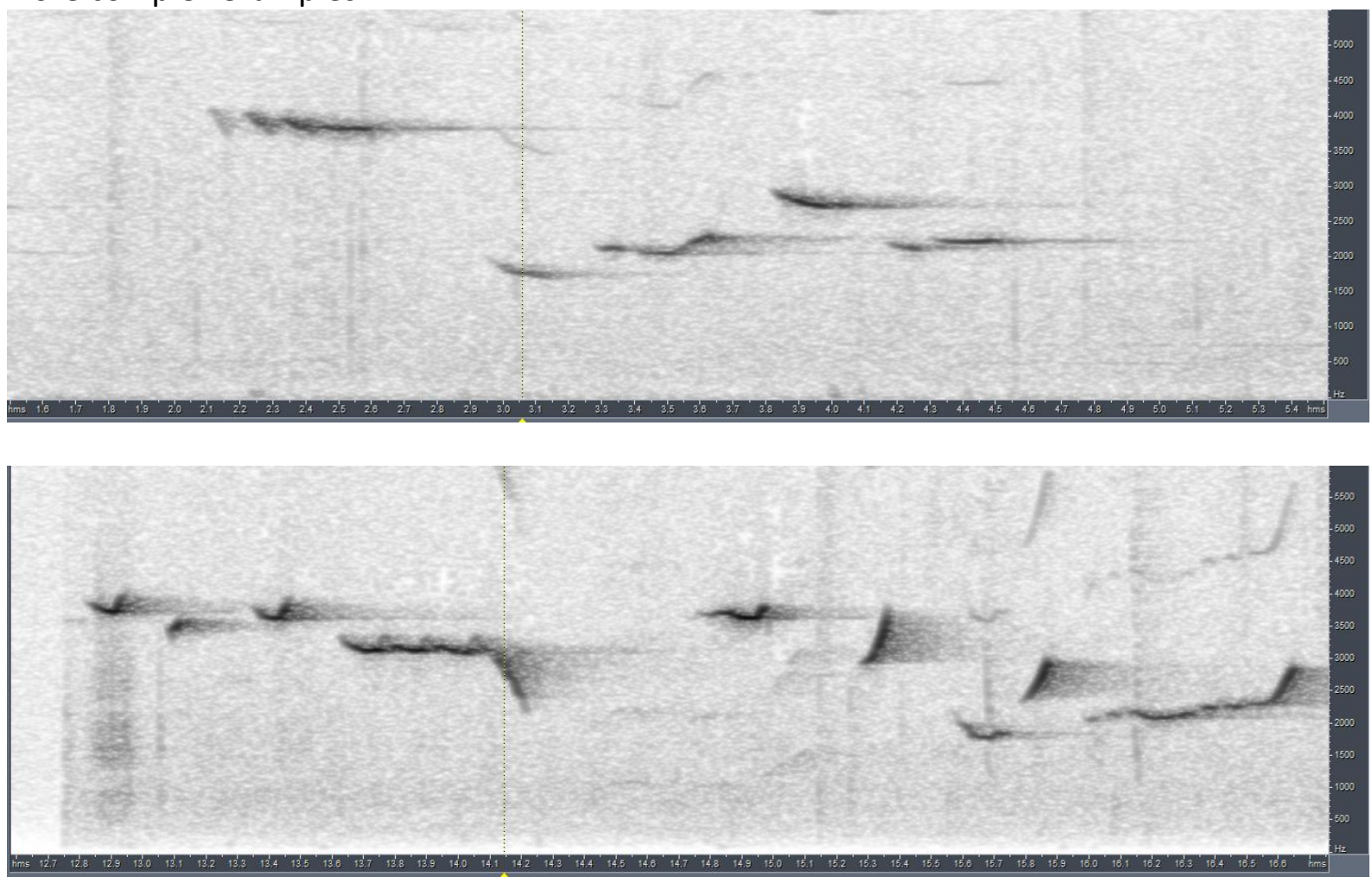

$(n=16)$

min. freq. (1st harmonic) $1670-3100 \mathrm{~Hz}$

max. freq. (1st harmonic) $3700-4240 \mathrm{~Hz}$

min. note length $\quad 0.06-0.12 \mathrm{~s}$

max. note length $\quad 0.21-0.60 \mathrm{~s}$

pace

$0.3-0.4 \mathrm{~s}$ (average)

notes repeated

6 - 9 (\# notes in simplest phrase) 

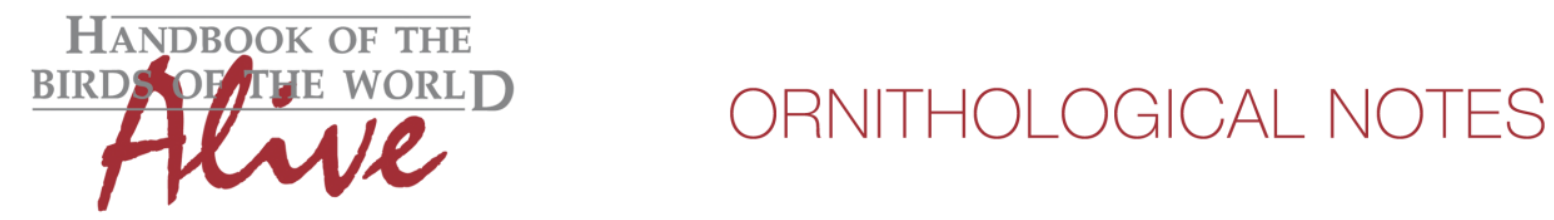

novaeguineae

We only located 2 recordings of this taxon. It seems to be quite similar to victorianus/dorsalis Example of descending series:

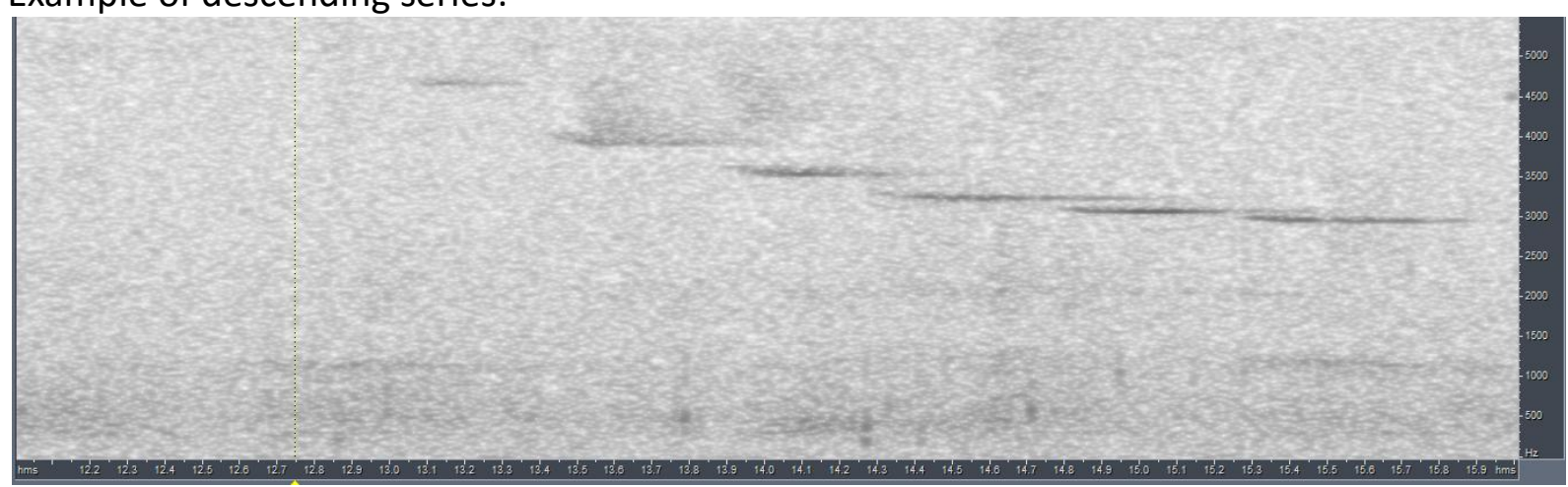

min. freq. (1st harmonic) $2250-3600 \mathrm{~Hz}$

max. freq. (1st harmonic) $4500-4650 \mathrm{~Hz}$

min. note length

max. note length

pace

c. $0.4 \mathrm{~s}$

notes repeated

6-7 (also short phrase of 3 notes?)

\section{Conclusion}

The dramatic difference in song between Australian and New Guinean Logrunner is reflected e.g. by temminckii having much lower-pitched notes (1st harmonic) (score 4), and having phrases of basically 1 note repeated (score 4). When applying Tobias criteria, this would lead to a total vocal score of 8 .

novaeguineae is similar to victorianus/dorsalis, but the few examples we have indicate a slightly higher max. frequency in the former.

This note was finalized on 7th August 2015, using sound recordings available on-line at that moment. We would like to thank in particular the sound recordists who placed their recordings for these species on XC and ML: Marc Anderson, Nick Athanas, Chris Benesh, Eleanor Brown, Scott Connop, Fernand Deroussen, Phil Gregory, Nigel Jackett, Niels Krabbe, Frank Lambert, Greg McLacklan and Mark Robbins.

\section{References}

Tobias, J.A., Seddon, N., Spottiswoode, C.N., Pilgrim, J.D., Fishpool, L.D.C. \& Collar, N.J. (2010). Quantitative criteria for species delimitation. Ibis 152(4): 724-746.

\section{Recommended citation}

Boesman, P. (2016). Notes on the vocalizations of Australian Logrunner (Orthonyx temminckii) and New-Guinean Logrunner (Orthonyx novaeguineae). HBW Alive Ornithological Note 155. In: Handbook of the Birds of the World Alive. Lynx Edicions, Barcelona. (retrieved from http://www.hbw.com/node/932085 on 17 August 2016). 